\title{
Da idealização à identificação: memórias afetivas em uma trajetória no Instituto Metodista de Ensino Superior
}

\section{From idealization to identification: affective memories along the journey at Methodist Institute}

Sueli Regina Gottochilich Rossini*

\section{Resumo}

Relato de trajetória acadêmica, discente e docente, no qual estão presentes aspectos pessoais com ênfase no desenvolvimento simultâneo do autor e do Instituto Metodista de Ensino Superior. Processos subjetivos são descritos, apoiados nas memórias afetivas, enquanto se apontam aspectos da realidade externa do campus, cenários para as experiências de vida. Conceitos psicanalíticos servem de apoio para compreender as vivências e a trajetória, assinalando a importância da instituição na representação psíquica.

Palavras-chave: trajetória acadêmica, memória afetiva, idealização, identificação, Instituto Metodista de Ensino Superior

\section{Abstract}

Report of academic journey as a student and teacher, stressing both the author's personal development and the successful story of Instituto Metodista de Ensino Superior. Subjective processes are described supported by affective memories, while aspects of campus external

* Psicóloga Clínica, Mestre em Psicologia da Saúde pelo Instituto Metodista de Ensino Superior, Doutora em Psicologia Clínica pelo Instituto de Psicologia da Universidade de São Paulo USP, Supervisora-Docente no Curso de Pós-Graduação em Psicoterapia Psicanalítica (CEPSI) na Universidade Paulista - UNIP 
reality (background to life experiences) are broached. Psychoanalytical concepts act as props to understand life stories and journeys, the importance of IMES in the psychic representation being pointed up. Keywords: academic journey, affective memories, idealization, identification, Methodist Institute

Na história as coisas acontecem uma vez só. É o tempo do "nunca mais". Tempo da morte. Mas as estórias são o tempo do "eterno retorno": basta que sejam contadas para que tudo aconteça de novo. ${ }^{1}$ Rubens Alves

O honroso convite para participar de um número especial comemorativo dos 45 anos do Curso de Psicologia, além de muito me emocionar, reavivou memórias de lugares, de situações e de pessoas que há muitos anos habitam dentro de mim, compõem minha história e são, de algum modo, coautores nesta escrita.

A trajetória de minha vida acadêmica, profissional e pessoal está de tal modo entrelaçada que não é possível mostrar uma sem evidenciar a outra. Assim, peço aos leitores que me acompanhem num percurso que começa bem antes da carreira docente. Cumpre avisar que não se trata de registros históricos ou documentais, mas sim de registros mnemônicos, intensamente carregados de emoções - memórias afetivas. Não seriam todas as memórias "afetivas"? Penso que sim. O acesso a muitas quase não demandou esforço e elas foram depressa assumindo a forma de relato; outras - preciosas - só vieram à tona enquanto ensaiava escrever o artigo. Não tinha nenhuma consciência das vivências a elas relacionadas. Surgiram impulsionadas pelas re-vivências.

\section{A idealização}

Do portão avisto a rua interna que sobe, quase em linha reta, ladeada de bonitas casas, tendo antes um edifício de poucos andares. Do outro lado, logo ali, à minha direita, uma grande e bela

ALVES, R. Um céu numa flor silvestre: a beleza em todas as coisas. Campinas: Verus, 2005, p.23. 
edificação. No meio da caminhada, o "bosque", como carinhosamente chamávamos o conjunto de árvores, que mais tarde daria lugar ao estacionamento e a alguns edifícios. E no final, arfante pelo passo apertado, encontro-me diante do majestoso Edifício Alfa, onde viveria, em diferentes oportunidades, momentos decisivos de minha vida acadêmica.

Estamos no início de 1973. Meus olhos ansiosos passeiam por tudo com curiosidade e absorvem com grande gosto as construções e os detalhes daquela imensidão que vou adentrando. Como é lindo aqui! É certo que contava na época 18 anos, estava iniciando a faculdade e vivia um turbilhão de emoções, além da influência do momento político e social e de vivermos no ABC Paulista. Mas as vivências da primeira experiência emocional do campus da Metodista jamais se diluíram, tendo sido reativadas em cada uma das inúmeras vezes que percorri, a pé ou de carro, o espaço entre o portão da Sacramento e os edifícios das salas de aula, seja como aluna da graduação ou da pós-graduação, seja como professora da casa.

Quando iniciei, aluna do curso noturno de Psicologia, o Instituto Metodista de Ensino Superior havia há pouco se formado - apenas três anos - e já contava mais de 400 alunos na área de Ciências Humanas. O Instituto e os novos cursos foram criados em função do crescente desenvolvimento da região (RUDGE RAMOS JORNAL, 2010). Recentemente, assistindo a uma entrevista com o então Diretor Prof. Luciano Ribeiro (METODISTA WEB TV, 2014a; METODISTA WEB TV, 2014b) tomei conhecimento de que o Instituto também pretendia suprir as despesas de manutenção decorrentes da área, grande e cara, ocupada pela Faculdade de Teologia.

No começo, as aulas aconteciam sempre no Edifício Alfa, construção datada de 1942²(PORTAL METODISTA, 2010; PREFEITURA MUNICIPAL DE SÃO BERNARDO DO CAMPO, 2015) de dois andares e quatro salas muito amplas. Um tempo de "aulas magnas": alunos do primeiro ano compartilhavam, quase em maioria, o currículo dos primeiro-anistas de outros cursos - era o chamado Curso Básico - e matérias como Língua Portuguesa e Língua Inglesa formavam, junto com Filosofia, Sociologia e Psicologia, a

$2 \quad$ Foi tombado como Patrimônio Público em 1987. 
nossa grade. Professores dedicados, amigos de interesses diferentes, disciplinas novas. A sensação era a de estar fazendo parte de algo muito importante e foi assim por um bom tempo. A bem da verdade, sempre que retorno ao campus, mesmo agora no Planalto, tenho a mesma experiência gratificante.

Os anos seguintes deram início à expansão do campus, com a construção do Edifício Delta, para o qual as aulas foram transferidas, sendo reservado ao Alfa, a partir de 1975, o Setor de Psicologia Aplicada: o andar de cima para as supervisões e o de baixo para os atendimentos, com as famosas salas de espelho. Vale lembrar que nos instalamos no Delta ainda com o piso de cimento, que aguardou um bom tempo para ver a cerâmica, sem que isso nada nos atrapalhasse, já que dispor de um prédio com muitas salas e recursos técnico-didáticos atendia perfeitamente as nossas necessidades de expansão interna e ampliação concreta, ambas interagindo e criando novas possibilidades. Pouco a pouco íamos aprendendo sobre percepção, comportamento e desenvolvimento humano, mecanismos de defesa, e toda uma imensa gama de conceitos e instrumentos que, mais tarde, iam situar-nos, ainda que precariamente, no iniciar da vida profissional. Tudo muito interessante e muito assustador também!

Alguns processos psíquicos são fundamentais no início do desenvolvimento emocional e entre eles salienta-se o mecanismo de idealização, que se manifesta - é bem verdade - ao longo de toda a vida, perante qualquer nova relação, seja com uma pessoa ou com uma instituição. Sua função é proteger-nos de nossos aspectos sádicos, cindidos e projetados no outro - persecutórios, portanto - permitindo-nos assim viver a experiência. Deve ele, entretanto, ceder lugar mais tarde à possibilidade de enfrentamento da realidade, tanto externa como interna, convergindo para uma integração dos aspectos positivos e negativos do objeto idealizado e para vivências mais realísticas da relação (KLEIN,1952/1978).

\section{Da identificação}

Impunha-se a necessidade de aprender e de participar da vida do campus, o que me obrigou, nos anos seguintes, a conciliar o horário de trabalho (e muita correria) com a monitoria para os colegas 
dos segundos e terceiros anos. Naquele momento, os primórdios de minha carreira docente estavam aflorando nas primeiras experiências relativas ao ensino e à pesquisa. Tempo de muito estudo e dedicação, desenvolvendo o embrião de uma parte da minha identidade profissional - sempre ensinando o que aprendia e sempre aprendendo com quem eu ensinava. Foi assim em Fisiologia, ministrada pelo Prof. Antonio Carlos, em Psicologia Experimental, com grande acolhimento das Profa. Marilda Fernandes Danna e Maria Benedita Lima Pardo, em Técnicas de Exame Psicológico quando se misturaram a paciência e carinho da Profa. Lídia Rodrigues Schwarz.

As monitorias encaixavam-se entre o final do expediente da repartição pública onde era funcionária e o início das aulas, depois de um dia inteiro de trabalho, o que perdurou até 1976, quando um expediente mais curto tornou possível aumentar a dedicação. Os frutos que colhi dessa experiência, o amadurecimento que ela trouxe transcenderam o conhecimento, a despeito da grande importância ao longo dos anos de consultório e de pesquisa. De cada uma delas posso enumerar os ganhos, mesmo quando parecem tão distantes do que hoje me ocupa e me norteia.

No começo do último ano da graduação, a faculdade anunciou um concurso interno para preencher duas vagas de auxiliar de ensino na disciplina de Psicologia Experimental, da qual eu vinha sendo monitora havia alguns semestres. Inscrevi-me com uma colega, prestamos o exame e fomos selecionadas. Era um cargo remunerado, com registro legal de funcionário da instituição, e consistia em auxiliar alunos e professores da disciplina nos exercícios práticos, nos grupos de discussão nas classes dos segundos e terceiros anos, entre outras atribuições. Grande alegria para nós podermos assumir, ainda estudantes, uma função docente. O prazer narcísico maior, entretanto, além do trabalho que realizávamos, era a Carteira de Trabalho com o primeiro registro da carreira. Nela se lê: Empregador- Instituto Metodista de Ensino Superior-IMS, registro que perpetuou o momento e a autoria.

O mecanismo de identificação, do ponto de vista da psicanálise, foi resumido muito claramente por Laplanche e Pontalis (1976) como "Processo psicológico pelo qual um indivíduo assimila um aspecto, uma propriedade, um atributo do outro e se transforma, total ou parcialmente, 
segundo o modelo dessa pessoa. A personalidade constitui-se e diferencia-se por uma série de identificações" ( p. 295).

Das intercambiações e das vicissitudes desse processo fundante e estruturante, de origem inconsciente, estabelecido mediante contínuas introjeções e projeções, resulta a estrutura de nossa personalidade. Inicia-se com as identificações com a mãe, ou melhor, com o seio da mãe e prossegue por toda a vida nas ligações afetivas com pessoas e instituições (KLEIN, 1955/1991). Tem papel fundamental nas relações amorosas, na capacidade de apaixonar-se, de comunicação e escuta do outro, e consiste na base de uma vida emocional satisfatória. Pode-se distinguir vários tipos de identificação em diferentes situações e momentos de nosso desenvolvimento.

Assim é que o curso me oferecia uma amplitude de situações nas quais eu ora ia me encontrando, ora me diferenciando, na busca de uma identidade. Não havia só estudo e trabalho: havia amigos, colegas da classe e de outras turmas, e os queridos e os temidos professores. Aulas torturantes com chamada oral - sim, prova oral de Neurologia - no terceiro ano. Sofríamos em conjunto, o que tornava mais suportável as inquisições do Prof. Luiz Carlos. Havia também as temidas arguições do Prof. Alvino, que ensinava as misteriosas e complexas interpretações do Rorschach. Ou ainda, a tortura das provas de Estatística. Tínhamos fugido da Matemática e eis que ela nos encontra. Tão tranquilizador separar os objetos "maus" e assim proteger os "bons", mas tão pouco efetivo para a aprendizagem e para o amadurecimento.

Entre o Alfa e o Delta se encontrava o prédio da cantina, que nos acolhia e abastecia de várias formas. Uma casa também antiga, provavelmente um anexo do Edifício Alfa quando da construção, onde nos sentávamos para comer algo, tomar café, ou simplesmente discutir questões acadêmicas e papear com amigos. Na parte baixa, numa espécie de porão bem instalado, o Diretório Acadêmico, que dava abrigo às nossas angústias sociais e políticas da época, que não eram poucas.

Nesse período, era Diretor Geral o Prof. Dr. Benedito de Paula Bittencourt, enquanto o Centro de Ciências era dirigido pelo Prof. Dr. Luiz Boaventura, e o querido Prof. Péricles de Oliveira Prado 
Filho era diretor da Faculdade de Ciências Humanas e Letras, a que estava filiado o curso de Psicologia.

O processo de identificação inicia-se com o nascimento e segue seu curso natural, se a pessoa é capaz de tolerar as diversidades e as adversidades, as suas próprias incongruências e as do outro.

No início do último ano da graduação, 1977, fui convidada para ocupar a função de auxiliar de ensino em uma faculdade de outra cidade da Grande São Paulo, na disciplina de Psicologia do Excepcional (assim denominada naquela época), convite da supervisora de um estágio extracurricular em andamento numa instituição que cuidava de crianças, jovens e adultos com moderada e grave deficiência intelectual e adaptativa. Também estagiava em uma clínica no Litoral Paulista voltada para o tratamento e educação de pessoas especiais.

A procura e o encontro de novos espaços e objetos de identificação é fator significativo no processo de individuação. A fixação no objeto idealizado impede o crescimento, aprisiona, esvaziando a relação e o sujeito.

No final da graduação, a gratificação, vivida em meio à dor da separação e ao temor de não ser capaz de existir longe do objeto idealizado. Introjeções mais amorosas e realísticas das figuras resultarão em processos mais saudáveis de separação e na possibilidade de desenvolvimento (KLEIN, 1952/1978) profissional e pessoal.

\section{O retorno}

Psicóloga graduada e com Licenciatura em Psicologia, eu continuava - agora longe da Metodista - minha carreira clínica e docente, lecionando em cursos de Psicologia de outras organizações educacionais, na função de Professora Assistente. Em setembro de 1978, a Profa. Maria Benedita Lima Pardo solicita afastamento do cargo para escrever sua dissertação de mestrado e recebo um convite para substituí-la até o final daquele semestre. Três anos depois, tenho a possibilidade de cobrir a licença-maternidade da professora da cadeira de Psicologia do Excepcional, Profa. Anna Maria Vieira Pires Gil, entre setembro e dezembro de 1981.

Por aquele tempo, a partir da experiência que vinha amealhando desde a graduação, junto com três colegas, abrimos no ABC uma 
clínica-escola voltada ao tratamento de pessoas com necessidades especiais. A clínica começou a receber alunos do curso de Psicologia que se interessavam por estágios extracurriculares supervisionados. Em maio de 1981, eu havia obtido o Certificado de Supervisor de Estágio em Psicologia Clínica, tendo preenchido as condições necessárias junto ao Conselho Regional de Psicologia, podendo atuar tanto em estágios na graduação quanto em aperfeiçoamento extra-acadêmico.

No final de 1981, recebo do Prof. Péricles a incumbência desafiadora de estruturar um programa para estágio supervisionado de atendimentos a excepcionais destinado aos alunos do $5^{\circ}$.ano. Estimulada pela solicitação e impulsionada pelo desejo de retomar a docência na Metodista, apresentei prontamente o programa que foi aceito e oferecido aos alunos.

Em fevereiro de 1982, tornei-me supervisora de estágios na área de clínica, tendo por mais de sete anos supervisionado quintanistas no atendimento a crianças e jovens com diferentes tipos de necessidades especiais, principalmente graves distúrbios no desenvolvimento cognitivo e emocional. Também acompanhei e orientei alunos no Atendimento Psicoterápico a Adultos.

Alguns dos professores que tive na graduação permaneceram por longos, longos anos no corpo docente da Metodista, o que me deu o privilégio de conviver com eles agora na condição de colegas de trabalho: o casal Maria Helena e Johannes Berkers, Profa. Eda Marconi Custódio, Profa. Laise de Castro Lira, Profa. Yassue Yamamura, entre tantos outros com quem sempre aprendi muito. Tive igualmente a oportunidade de reencontrar colegas da formação ora lecionando na graduação, ora supervisores na clínica, ou em cargos de coordenação. Íamos nos desenvolvendo sob a proteção e o acolhimento da instituição-mãe.

Tempo de muitas experiências e muita aprendizagem, de reuniões e discussões de planejamento. A Psicologia, por essa época, ganhava espaço e tornava-se mais conhecida e necessária em diversos âmbitos, estimulando uma busca significativa pelo curso. Jovens recém-saídos do colégio e adultos vindos de outras profissões buscavam a graduação, tanto no período diurno como no noturno. O Instituto Metodista experimentou um crescimento 
impressionante, não apenas na Psicologia, mas em todos os cursos oferecidos. A "obrigação" do diploma universitário impunha-se à sociedade, multiplicando a oferta de cursos e o número de vagas.

Em 1986, o Instituto contava com cerca de 8000 alunos distribuídos nos diversos cursos de graduação e pós-graduação (METODISTA WEB TV, 2014). Não tardou então que novos edifícios encontrassem lugar no campus e que a paisagem aos poucos fosse assumindo o aspecto monumental de hoje.

Ainda como professora da casa e com o privilégio de bolsista da instituição, pude iniciar meus estudos de pós-graduação em Psicologia da Saúde, tendo mais uma vez encontrado docentes de grande capacidade e dedicação, cuja influência levou-me a distinguir novos vértices de observação.

Meu trabalho na supervisão dos alunos estava basicamente concentrado no atendimento de crianças e jovens especiais, incluindo orientação aos pais. A maioria dos pacientes passava pelo processo de psicodiagnóstico, também no Setor de Psicologia, após o que eram encaminhados para o atendimento especial. É importante ter em mente o momento do conhecimento e da abordagem às pessoas com diferenças do padrão, fossem elas cognitivas, motoras ou emocionais. Nem de longe se cogitava em inclusão escolar e àqueles que não conseguiam acompanhar o ensino oferecido pelas escolas ditas "normais" sobravam pouquíssimas opções, ainda menores dependendo das condições financeiras e da gravidade da limitação. Os municípios com melhores condições tinham seus próprios centros de educação e tratamento (caso de São Bernardo do Campo, com os Núcleos de Educação Especial, que abrangiam toda a parte pedagógica e também de profissionalização) ou as associações de pais, como APAE (caso, na região, dos municípios de Santo André, São Caetano e Diadema, este último de inauguração recente na época). Os pacientes apesentavam dificuldades acentuadas e diversas. Tanto recebíamos crianças nos primeiros anos da escolaridade com queixas de aprendizagem, como havia outras cujos problemas emocionais eram tão graves que dificultavam ao extremo ou mesmo impossibilitavam o convívio escolar naquele momento. Não era tampouco raro procurar-nos famílias de jovens que, depois 
de ter passado por escolas especiais, já não conseguiam adaptar-se às oficinas, fossem pedagógicas ou abrigadas.

Na maioria das vezes o sofrimento estava na restrição das perspectivas de desenvolvimento considerando a escolaridade normal, geralmente o grande desejo da família. O atendimento era muito individualizado, por vezes com foco em aspectos adaptativos, mas a ênfase sempre esteve nas condições emocionais do paciente, as quais dificultavam o acesso ao ensino que era oferecido e à participação na sociedade. $\mathrm{O}$ atendimento aos pais era peça fundamental nesse trabalho, visto que as aflições experimentadas pela família produziam consequências diretas na autoestima do paciente e em suas possibilidades de lidar com os desafios impostos pelo crescimento e pelas demandas sociais.

Das angústias vividas nos anos de supervisão junto com meus queridos alunos surgiu a necessidade de saber e de sistematizar um pouco mais sobre os familiares, sobre as relações entre eles e o mundo interno dos pacientes atendidos na clínica. Essas indagações tomaram forma ee deram corpo a um projeto ancorado na Teoria das Relações Objetais, de Melanie Klein, propondo estudar o dinamismo psíquico de famílias de excepcionais, não somente a criança ou o jovem, mas incluindo o pai e a mãe. Meus alunos participaram dessa empreitada comigo, tendo sido os responsáveis por aplicar os instrumentos, uma vez que atendiam os pacientes no programa de estágio supervisionado. Estudamos os instrumentos, treinamos a aplicação e a correção. Intensa aprendizagem, marcada pela angústia de tomar contato com dores tão intensas e primitivas e pelas limitações de recursos oferecidos às famílias. Os resultados foram organizados na minha dissertação de Mestrado em Psicologia da Saúde, orientada pelo Prof. Dr. José Tolentino Rosa, intitulada "Percepção de Relações Objetais em Famílias de Excepcionais: um estudo com o Teste de Phillipson", defendida em 1988 perante o Programa de Pós-graduação do Instituto Metodista.

A docência no Instituto se estenderia apenas por mais um semestre, quando motivações familiares e pessoais me levaram a solicitar o desligamento.

Na verdade, fiquei afastada da docência por um período longo demais para mim, a ela voltando, anos depois, em outra instituição 
e em outra área de estudo. Refletindo hoje, creio que foi preciso me afastar da docência para lidar com o desligamento da Metodista que, naquele momento, não me oferecia a possibilidade de avançar na carreira.

\section{Considerações finais}

Fui da quarta turma de Psicologia da Metodista, embora, até alguns anos atrás, tinha plena convicção de ter sido da segunda. $\mathrm{Na}$ minha fantasia, eliminei os irmãozinhos da segunda e da terceira turmas - o ciúme é um sentimento muito potente mesmo. Tenho muito orgulho de ter sido das primeiras turmas, de ter iniciado e desenvolvido minha carreira profissional em um ambiente protetor, amoroso e ao mesmo tempo estimulante e desafiador.

Finalizando, falta relatar algo muito importante. Havia um parquinho para crianças, onde atualmente encontram-se uma capela, provavelmente instalado muitos anos atrás, para as crianças, filhos dos pastores e professores metodistas que residiam no campus. Muitas e muitas vezes, fui ao campus para alguma atividade rápida e levava meus filhos, que me aguardavam ali brincando na "balança, no trepa-trepa", etc... Adoravam me acompanhar ao trabalho - principalmente o mais velho - e contar com essa diversão extra, além da cantina, certamente. Ainda hoje ele se recorda do parquinho, dos brinquedos que havia e até de uma colmeia de abelhas que fazia com que, muitas vezes, o local ficasse interditado, para tristeza dele e da criançada que ali aportava. Acredito que todas essas idas ao campus com meus filhos e o carinho com que sempre me referia à Metodista estão na base da escolha dele por um curso na Universidade Metodista, pelo estágio lá realizado, por ter, também ele, começado sua carreira profissional, já formado, na instituição . A estima e a consideração que ele tem pela instituição, pelos colegas de turma e de trabalho, pelos professores e pelo campus até hoje são compartilhados com a mãe.

Orgulho de ser METODISTA! Experiências que me identificam e História e estórias com a qual me identifico, responsáveis por boa parte do que hoje sou como pessoa, docente e psicoterapeuta. 


\section{Referências}

KLEIN, M. Algumas conclusões teóricas sobre a vida emocional do bebe. In: KLEIN, M.; HEIMANN, P; ISAACS, S; RIVIERE, J. (Orgs.). Os progressos da Psicanálise. Rio de Janeiro: Zahar Editores, 1978. p. 216-255. (original de 1952).

KLEIN, M. Sobre a Identificação. In: KLEIN, M. (Org.) Inveja e Gratidão e outros trabalhos (1946-1963). Rio de Janeiro: Imago, 1991. p. 169-206. (original de 1955)

LAPLANCHE, J. ; PONTALIS, J.B. Vocabulário da Psicanálise. 3a.ed. Lisboa: Moraes Editores, 1976.

METODISTAWEB TV. Otoniel Luciano Ribeiro: 44 anos de história no instituto Metodista de Ensino Superior $1^{a}$.parte. Disponível em: <https://www.youtube.com/ watch?v=0dkRvnghefo> Publicado em 19/12/2014. Acesso em 12 maio de 2016.

METODISTAWEB TV. Otoniel Luciano Ribeiro: 44 anos de história no instituto Metodista de Ensino Superior - O início, 2a . parte. Disponível em:

$<$ https://www.youtube.com/watch?v=NkWtmtG8ZmY> Publicado em 19/12/2014. Acesso em 11 maio/2016.

PORTAL METODISTA. Marco histórico: inaugurado o Centro de Memória Metodista. Disponível em: < http://portal.metodista.br/fateo/noticias/inaugurado-ocentro-de-memoria-metodista/> Publicado em 03/09/2010. Acesso em 10 maio/2016.

PREFEITURA DE SÃO BERNARDO DO CAMPO. Edifício Alfa, no campus da Metodista, é patrimônio histórico. Disponível em <http://www.saobernardo.sp.gov. br/historiadacidade/-/asset_publisher/iykrFCtxYcvR/content/edificio-alfa-no-campus-da-metodista-e-patrimonio-historico/maximized >. Acesso em 5 maio/2016

RUDGE RAMOS JORNAL. Instituto Metodista de Ensino Superior comemora 40 anos. Disponível em: <http://www.metodista.br/rronline/rrjornal/2010/ed948/instituto-metodista-de-ensino-superior-comemora-40-anos > Publicado em 19/08/2010. Acesso em 5 maio/2016.

ROSSINI, S.R.G. Percepção das Relações Objetais em Famílias de Excepcionais: um estudo com o Teste de Phillipson. Dissertação (Mestrado). São Bernardo do Campo, SP: Instituto Metodista de Ensino Superior, 1988.

Contato da Autora:

Rua Catequese, 1149, conjunto 93. B. Jardim. Santo André- SP

CEP 09090-401 telefones: (11) 49929539 (11) 996950211

e-mail: suelirossinipsico@yahoo.com.br

Recebido em: 02/05/2016

Aceito em: 28/06/2016 